\title{
The Effect of Utilization of Movie Media on Learning Achievement Related to the Western Civilization Learning among Freshmen Nursing Students
}

\author{
Pisit Phuangnak, Kornwika Phromjuang, and Napadon Leaudnakrob
}

\begin{abstract}
The study was to explore the effect of utilizing of movie media on learning achievement related to the Western civilization learning in a civilization and local wisdom subject among freshmen nursing students $(n=78)$ at Boromarajonani College of Nursing Uttaradit. Questionnaires consisted of 1) Digital Versatile Disc (DVD) movies related to the "Western civilization: Greek, Roman, and Egypt civilizations" (6 movies) by utilizing on collaborative learning, 2) learning achievement measurement on the "Western civilization", and 3) the freshmen nursing students' perception on the utilization of the movie media related to the "Western civilization". Statistical analyses were utilized on mean, Standard Deviation $($ S.D. $)$, and paired- $t$ test $(p<.05)$. Findings revealed that learning achievement on the Western civilization by performing on collaborative learning after utilizing on the movie media $(X=32.27$, S.D. $=4.37)$ was statistically significant higher than before utilizing on the movie media $(X=23.15, S$.D. $=6.25)(p<.05)$. The freshmen nursing students' perception on utilizing of the collaborative learning placed on a high level $(X=$ 4.17, S.D. = 0.21). The nursing students mostly reported that the DVD movies could stimulate the interesting in the civilization and local wisdom subject among learners because of the movies' modern styles that were suitable for the learners. When they did not catch up on content in each chapter, they could study on the chapter related to the DVD movies and revive if they desired.
\end{abstract}

Index Terms-Movie media, digital versatile disc, the western civilization, and collaborative learning.

\section{INTRODUCTION}

Learning and teaching media play a key role for learning and teaching management because they mediate on improving effective communication between instructors and learners during studying. Learners could be easily able to understand content on each lesson. It could encourage learners with having humorous, creating innovation, and improving on participation of learning and teaching activities [1]. Currently, technology media are popular such as

Manuscript received February 10, 2013; revised April 30, 2013

N. Leaudnakrob, P. Phuangnak, K. Phromjuang, and P. Poltana are with the Center of Excellent for Innovative Teaching and Learning Praboromarajchanok Institute for Health Workforce Development (PIHWD), Ministry of Public Health, Thailand (e-mail: 1_napadon@ hotmail.com, pisit_p2503@yahoo.com,kxp52@yahoo.com, ppoltana@hotmail.com).

P. Phuangnak is with Boromarajonani College of Nursing, Uttaradit (UNC) under PIHWD, Ministry of Public Health, Amper Muang, Uttaradit Province, 53000 Thailand.

K. Phromjuang is with Boromarajonani College of Nursing, Buddhachinaraj (BNC) under PIHWD, Ministry of Public Health, Amper Muang, Pitsanulok Province, 65000 Thailand.

K. Phromjuang is with Boromarajonani College of Nursing, Uttaradit (UNC) under PIHWD, Ministry of Public Health, Amper Muang, Uttaradit Province, 53000 Thailand. multimedia, electronic books (e-books), Computer Assisted Instruction (CAI), video, movies, slides, tape, and other electronic media. Those media could apply on learning and teaching to translate content and knowledge to learners such as having response on each individual difference [2]. Learning and teaching management, on the "Western civilization" in the civilization and local wisdom subject among freshmen nursing students about 9 hours at Boromarajonani College of Nursing Uttaradit, was to provide learners to understand the "Western civilization such as Greek, Roman, and Egypt civilizations" that still existed as evidence. However, problems of learning and teaching management on learning achievement of learners were under standardized based on instructors' need. In 2009, the learning achievement's evaluation showed that learners $(15 \%)$ had under standardized relied on instructors' need, causing from instructors such as communicated limitation from lecturing with power point presentation with slides. It considered one way communication [3] that was the instructor-centered teaching instead of the student-centered teaching on each session. It made students boring of learners and low interested in content and studying, leading to diminish effectively teaching and learning management and decrease of students' satisfaction on that subject.

Thus, researchers utilized the DVD movies related to the "Western civilization such as Greek, Roman, and Egypt civilizations" with managing on collaborative learning. After watching on the DVD movies to generate learning achievement related on the "Western civilization" that inquired on the Civilization and Local Wisdom subject, it revealed that was useful to expand on learning and teaching management between instructors and nursing students.

Objectives of the study were 1) to explore learning achievement before and after of utilizing on the DVD movie media incorporated with learning and teaching management on the "Western civilization". 2) to study on freshmen nursing students' perception on managing by utilizing on the DVD movie media incorporated with learning and teaching management by using on collaborative learning on the "Western civilization".

\section{LiterATURE REVIEW}

Collaborative learning is one of methods of learning. It opens opportunity for learners who can learn together with groups to study on area of interesting by utilizing on learners' knowledge, experience, and external information. In order to generate a piece of work by presenting products such as showing idea, discussion, and critiques, it emphasized on participation and interaction between learner groups [4] by a 
group investigation. It is learning technique, and it could effectively apply on collaborative learning. Learners' group indentified roles on each person in the group [5]. The group investigation was developed from a concept of inquiry of knowledge and a concept of knowledge by operating on problems to activate learners' feeling, require to search data, or search of knowledge. It caused learners to practice on searching skills. They could inquiry by themselves [6]. Learning and teaching management based on the lifelong learning in the Information Technology's (IT) era should be performed.

The DVD movie media are the one part of the computer technology that can be able to manage on learning and teaching management by utilizing on electronic learning (e-learning). Recently, these media are popular and durable media, and they also are easily various functions on convenient operation. Learning and teaching management by using on the DVD movies will stimulate learners' interesting, leading learners' thinking skills such as before, during, and after watching on those movies [7]. Currently, learning from the computer technology was changing learning and teaching styles especially on the DVD movies that learners could study anywhere in the world or 24/7. This research was conducted by utilizing on the DVD movies as the instrument in this research that created recreation and symbols of the Greek, Roman, and Egypt civilizations.

Learning and teaching on the civilization and local wisdom subject in Chapter II on the "Western civilization: Greek, Roman, and Egypt civilizations" was educated on five components that human created the civilization. First, socialization means co-dwelling, working, classifying, grouping, and conflicting. It would imply that the civilization includes on human successfulness and extending settlement. Second, economic indicates exchanging or allocating resources such as creation of productive activity, distribution, consumption, and identification on financial system. Third, art represents human social status that is autonomy or symbols. It is good evidence on studying of civilization on society such as fine art, literature, and architecture. Fourth, politic signifies social arrangement or managing on sovereignty such as enacting laws, keeping on power of politic, gathering groups, and employing war. Fifth, wisdom denotes on understanding with other such as creating knowledge system, generating belief, establishing science, producing knowledge and fundamental technology, and constructing other theories, etc.

\section{Methodology}

Quasi experimental design was conducted to develop the learning of the "Western civilization: Greek, Roman, and Egypt civilizations". The freshmen nursing students' perception on the utilization of the movie media related to the "Western civilization" was assessed after nursing students' learning from lecturing by an instructor on the civilization and local wisdom subject about 9 hours and self study around 12 hours. Questionnaires consisted of 1) DVD movies related to Greek, Roman, and Egypt civilizations, 2) four multiple choices (45 items) of pre-test and post-test after learning on the "Western civilization" were examined, and Conbarch's alpha was analyzed $(\alpha=0.92), 3)$. For the freshmen nursing students' perception (62 items) on the utilization of the DVD movie media related to the "Western civilization" with 5 rating scales such as strongly agree (5), somewhat agree (4), moderated agree (3), somewhat disagree (2), and strongly disagree (1), Conbarch's alpha of the freshmen nursing students' perception related to satisfaction was analyzed $(\alpha=$ 0.82 ). Learners' satisfaction contained of 5 levels such as strongly agree (4.21-5.00), somewhat agree (3.41-4.20), moderated agree (2.61-3.40), somewhat disagree (1.81-2.60), and strongly disagree (1.00-1.80), respectively.

Data collection was done on the pre-test gathering before watching on the DVD movies (6 movies) related to the "Western civilization" with the collaborative learning. The post-test was collected (45 items) with testing of the freshmen nursing students' perception on the utilization of the movie media related to the "Western civilization". Statistical analyses were utilized on mean, Standard Deviation (S.D.), and paired- $t$ test $(p<.05)$.

\section{RESULt}

Findings discovered that learning achievement on the "Western civilization" by performing on the collaborative learning after utilizing on the movie media $(X=32.27$, S.D. $=$ 4.37) was statistically significant higher than before utilizing on the movie media $(X=23.15$, S.D. $=6.25(p<.05)$. The freshmen nursing students' perception on the utilization with the collaborative learning placed on the high level $(X=4.17$, S.D. $=0.21)$.

\section{DISCUSSION AND CONCLUSION}

Findings considered that learning achievement on the Western civilization by performing on the collaborative learning after utilizing on the movie media was statistically significant higher than before utilizing on the movie media ( $p$ $<.05)$ that followed to a hypothesis. The reasons, why the mean of learning achievement after learning with the DVD movies was higher than before because the media could fashion learners able to learn content related to five components that human created the civilization such as socialization, economic, art, politic, and wisdom, discussed above. Learners could be able to study from the DVD movies related to the "Western civilization" entitled Troy, The Mummy, Gladiator, and Cleopatra, and 300 knights shocking world. Researchers assigned learners to exchange questions on each ambiguous problem with their friends via the instructor and electronic mail with the collaborative learning and the group investigation. It motivated learners to exchange learning with each other and formed body of knowledge from the DVD movies and the IT. Because of learners had to search and generate knowledge by themselves with working as teams, they were consulting each other all time. They were also working orderly and having principle and science. The mobilized pictures and VDO are new media in this era that distribute all over the world called "World knowledge asset". There is a lot of knowledge that generates all time and easily searches from the IT, including inquiry of 
things that people need to know [8]. The learning achievements were higher after learning with the DVD movies than before. The nursing students mostly reported that the DVD movies could inspire the interesting in the civilization and local wisdom subject among learners because of the movies' modern styles that were suitable for the learners and they could learn from their neuron systems such as perception from simultaneous vision and hearing [9]. Selecting the DVD movies related to the Greek, Roman, and Egypt civilization as the media was important that could educate learners based on aiming and objectives of learning and teaching management with different events and learning and teaching' activities. It would make learners having great attitude and motive on learning [10]. The DVD movies were suitable for learning and teaching management on both each person and groups from advantages of animation pictures and sound [1]. All processes of learning based on Bloom's taxonomy posited that learning behavior relied on brain functioning with six steps from the lowest to the highest such as cognition and knowledge, understanding, application, analysis, synthesis, and evaluation [11].

The freshmen nursing students' perception on the utilization with the collaborative learning on the "Western civilization" placed on the high level. On each component, mostly they agreed with the high level in all aspects from the most to the least opinion such as benefits on receiving learning with the DVD movie media in learning and teaching management among nursing students. The DVD movies on learning and teaching management on the "Western civilization", Learning Management System (LMS), and learning and teaching activities with collaborative learning via the DVD movie media should be taught among nursing students. They performed authentically learning in digital environment that enhanced nursing students to use ability on the IT and communication in collaborative working. The interaction between learners and instructors could be implemented in anytime and anywhere in the world, leading to perceiving benefits from learning together via the DVD movies. Movies had have activity in each step, causing learners created thinking skills and analyses to create body of knowledge related to the "Western civilization". While watching the DVD movies, it should harmonize with teaching in the pre-watching step on the DVD movies, during watching the DVD movies, and after watching them [7]. Learning environment by integrating with suitably educational technology and identifying methods of utilizing electronic device could be practical. Moreover, other techniques to appropriately resolve problems and learning and teaching events in a classroom had better utilized [12]. Presently, the operation of technology with the collaborative learning of other media such as power point slides and mobile slides can boost the educational and training effectiveness. The power point and movable slides consists of multi-visual slides, video, Compact Discs (CD), DVD, and world wide web (www) [13] that all media would encourage interesting and promote supporting learners to having knowledge and skills from increasing on learning experiences [14]. According to the LMS, it should facilitate learners, instructors, and computer administrators who supervise the IT system based on learning managing components such as managing curriculum system, creating lesson system, testing and evaluating system, supporting learning system, and administering data system [15].

\section{RECOMMENDATION}

Selecting movies utilized in learning activities should not be outdated, fitting content with the lesson on the "Western civilization" in learning and teaching management. Nursing students would reflex pictures of developing on early civilization to new civilization until now.

Instructors had better selecting movies according to the "Western civilization" lesson. They should understand on content of the movies before utilizing them in the learning activity management. They also should deal with learning activities to learners who can learn by themselves and participate in opinion together.

Instructors should function as stimulators and provide recommendation on the collaborative learning activities via the DVD movies based on lessons or concept's need. The learners produce the collaborative learning, including invent environment in the classroom by constructing the most thinking and practicing of learners.

\section{CONCLUSION}

After finished watching the DVD movies, teachers and learners should discuss and analyze together related on the "Western civilization" such as socialization, economic, art politic, and wisdom that demonstrated in the movies. The narrative interviewing or report from watching on the movies should be shaped in order to generate new knowledge for learning and teaching management in the IT era. Teachers should promptly argue with nursing students who are studying with collaborative learning in the groups and clarify if they are still doubt on movie media. For nursing schools, DVD players and movies should be available to lend in weekends. Thus, nursing students could have more time to study on the "Western civilization".

\section{ACKNOWLEDGMENT}

Researchers would like to thank you for the freshmen nursing students at Boromarajonani College of Nursing Uttaradit (UNC) to participate in this study.

\section{REFERENCES}

[1] B. Tunhikorn, "Apply of Information Technology (IT) in learning andteaching," Bangkok: The Information Technology project based on Somdech Phra Debaratanarajasuda Chao Fa Maha Chakri Sirindhorn Rathasimagunakornpiyajat Sayamboromrajakumari, The Technology electronic and computer national center, 2008.

[2] A. J. Al-Ajlan and H. Zedan, "Why Moodle," in Proc. $12^{\text {th }}$ IEEE international Workshop on Future Trends of Distributed Computing Systems, pp. 58-64.1959.

[3] G. G. Bitter, Using technology in classroom, $7^{\text {th }}$ ed., Boston: Pearson/ Allyn and Bacon, 2008.

[4] P. Thongdeereit, "Presentation on learning module on computer network for a bachelor degree with different learning modules," Dissertation of Philosophy Doctor. Information and Communication Technology for Education. Graduate study, Chulalongkorn University, 2004.

[5] S. Meungsai, "Collaborative learning development by utilizing of Problems Based Learning (PBL) that enhances learning capacity via 
computer networks," Master thesis on Faculty of Computer Education Faculty of Computer Education of King Mongkut's University of Technology North Bangkok or Technology Pranakorn Nuah, 2009.

[6] T. Kaemanee, Teaching science: Body of knowledge on effectively learning process management, $3^{\text {rd }}$ ed., Bangkok: Chulalongkorn University Press, 2004.

[7] A. Sangaroonlert, "Utilization of movies to develop writing skills on English and critical thinking among progressive students," Chaingmai: Chaingmai University graduate department, 2008.

[8] P. Pakamart, ICT system and modern management, Bangkok: Witty group, 2010.

[9] K. Doney. (2000). Firm for Fluency. [Online]. Available: http://www.eric.ed.

[10] W. H. Allen, "Media stimulus and types of learning," Audiovisual Instruction, pp. 27-31, January 12, 1967.

[11] L. A. Halawi, R. V. McCarthy, and S. Pires, "An evaluation of e-learning on the basis of Bloom's taxonomy: An exploratory study," Journal of Education for Business, vol. 84, pp. 374-380, 2000.

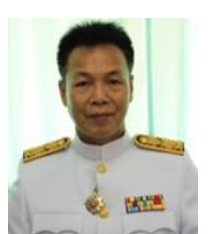

Pisit Phuangnak was born at Nakornsawan Province, Thailand in 1960. He graduated from Sirindhorn College of Public Health, Pitsanulok on an associated degree in 1983. He also got a bachelor degree in Public Health from Mahidol University in 1991 . He is currently a full-time lecturer at the General of Education department at Boromarajonani College of Nursing Uttaradit (UNC). His research focuses on statistics and research related on public health.

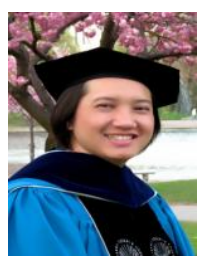

Kornwika Phromjuang was born at Uttaradit Province, Thailand on October 25, 1973. She got a diploma on nursing science equivalent to Bachelor of Science in Nursing on March 15, 1995 from Boromarajonani College of Nursing, Uttaradit (UNC), Praboromarajchanok Institute for Health Workforce Development (PIHWD), Ministry of Public Health, Thailand. She graduated in Nursing Administration on her $1^{\text {st }}$ Master in the Nursing Science (M.N.S) degree on June 4, 1999 from Faculty of nursing, Chulalongkorn University, Bangkok, Thailand. On April 15, 01, she got the Royal Thai Government Scholarship for furthering study in Master and $\mathrm{PhD}$ programs focusing on Gerontological nursing in the U.S.A. from the PIHWD, Ministry of Public Health, Thailand on July 29, 2002 for studying on MSN and PhD at the U.S. She was graduated in the $2^{\text {nd }}$ Master Science in Nursing (M.S.N) on January 14, 2005 on Clinical Nurse Specialist (CNS) focusing on acute care on medical-surgical nursing from France Payne Bolton School of Nursing (FPB) Case Western Reserve University (CWRU), Cleveland, OH, U.S.A. She was also graduated on her $\mathrm{PhD}$ (gerontological nursing) on May 18, 2008 from the FPB, CWRU, Cleveland, OH, U.S.A. as well.

Dr. Phromjuang was working as a nursing instructor from 1995 to 2002 at the UNC before going to study on the master and $\mathrm{PhD}$ at the U.S.A. After she graduated on her PhD in 2008, she was working at Boromarajonani College of Nursing, Lampang under the PIHWD as a professional level from 2008-2010. She has been working as the nursing instructor on a senior professional level at Boromarajonani College of Nursing, Buddhachinaraj (BNC) at Pitsanulok Province under the PIHWD since June, 2010. Her research interests focus on health promotion behavior among diabetic elderly, wound care nursing, pain management, emergency nursing, and clinical nursing related to elderly patients on acute care.

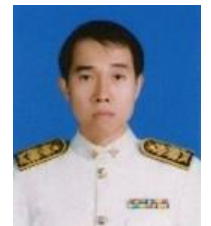

Napadon Leaudnakrob was born at Prae Province, Thailand in 1972. He got a diploma on nursing science equivalent to Bachelor of Science in Nursing in 1993 from Boromarajonani College of Nursing, Sawanpracharak, Praboromarajchanok Institute for Health Workforce Development (PHWD), Ministry of Public Health, Thailand. He also graduated in a master's degree of Medical Science (M.S.) in Medical Physiology from Khon Kaen University in 1999. He is currently a lecturer at the Boromrajonani College of Nursing Uttaradit (UNC). His research focuses on e-learning, measurement and evaluation, and Internet Computer Technology (ICT). 